\title{
On the Ultra-Low-Frequency Magnetic Field Depression for Three Huge Oceanic Earthquakes in Japan and in the Kurile Islands
}

\author{
M. Hayakawa ${ }^{1,2,3}$, A. Schekotov ${ }^{4}$, E. Fedorov ${ }^{4}$ \& Y. Hobara ${ }^{5}$ \\ ${ }^{1}$ Hayakawa Institute of Seismo-Electromagnetics Co., Ltd., University of Electro-Communications (UEC), \\ Incubation Center, 1-5-1 Chofugaoka, Chofu Tokyo, Japan \\ ${ }^{2}$ UEC, Advanced Wireless Communications Research Center, Chofu Tokyo, Japan \\ ${ }^{3}$ Earthquake Analysis Laboratory, Kita-aoyama 2-12-42-R305, Minato-ku Tokyo, Japan \\ ${ }^{4}$ Institute of Physics of the Earth, Russian Acad. of Sciences, 10 Bolshaya Gruzinskaya, Moscow, Russia \\ ${ }^{5}$ UEC, Graduate School of Informatics and Engineering, Chofu Tokyo, Japan \\ Correspondence: M. Hayakawa, Hayakawa Institute of Seismo-Electromagnetics Co., Ltd., University of \\ Electro-Communications (UEC), Incubation Center, 1-5-1 Chofugaoka, Chofu Tokyo, Japan. Tel: \\ 81-424-446-349. E-mail: hayakawa@hi-seismo-em.jp
}

Received: August 7, 2012 Accepted: August 17, 2012 Online Published: September 6, 2012

doi:10.5539/esr.v2n1p33 URL: http://dx.doi.org/10.5539/esr.v2n1p33

\begin{abstract}
The depression (reduction in amplitude) of ULF (ultra-low-frequency) magnetic field variations observed on the Earth's surface is found for the recent huge Japan earthquake (EQ) (magnitude (M) 9.0) on March 11, 2011 which is a typical oceanic EQ of the plate type. In order to confirm the presence of such a ULF depression, we have also studied the additional two huge oceanic EQs in the Kurile islands $(\mathrm{M} \cong 8)$, and similar ULF depressions have also been detected. This suggests that such a ULF depression seems to be a universal phenomenon for huge $(M=8-9)$ EQs even occurred in the sea bed of subduction region.
\end{abstract}

Keywords: ULF magnetic field depression, oceanic EQs, EQ precursor, EQ prediction

\section{Introduction}

It is recently thought based on the extensive studies during the last few decades that electromagnetic phenomena do appear prior to an earthquake (EQ) (e.g., Hayakawa \& Molchanov, 2002; Pulinets \& Boyarchuk, 2004; Molchanov \& Hayakawa, 2008), including the lithospheric phenomena (such as geoelectric field, ULF (ultra-low-frequency, frequency less than $10 \mathrm{~Hz}$, but mainly in the $\mathrm{mHz}$ range) electromagnetic emissions, etc.), and seismo-atmospheric and-ionospheric perturbations. The most convincing effect at the moment might be the ionospheric perturbations as detected by subionospheric VLF/LF propagation, because there has been established a significant statistical correlation between the ionospheric perturbations and inland EQs with magnitude(M) greater than 6.0 and with depth smaller than $40 \mathrm{~km}$ (Hayakawa et al., 2010).

Among the lithospheric effects, the ULF electromagnetic emissions are found to be promising for EQ prediction, though the number of events is not so abundant as compared with the ionospheric perturbations mentioned above (e.g., Hayakawa et al., 2007; Fraser-Smith, 2009; Kopytenko et al., 2009). The first ULF event was observed for the Spitak EQ in 1988 (Kopytenko et al., 1990; Molchanov et al., 1992), and Fraser-Smith et al. (1990) found an evidence of ULF signature of the 1989 Loma Prieta EQ (M=7.2). Hayakawa et al. (1996) then found the ULF emissions in the case of the 1993 Guam EQ $(M=8.0)$. Later ULF studies have been summarized in Molchanov and Hayakawa (2008), Hayakawa et al. (2007) and Hattori (2004), though there have recently been published few papers casting a doubt to the presence of seismogenic ULF emissions (Campbell, 2009; Masci, 2011).

A different type of ULF anomaly of EQ effects has been found by Molchanov et al. (2003) and Schekotov et al. (2006). Being completely different from the above seismogenic lithospheric ULF emissions, this new effect is a phenomenon in the form of depression in the amplitude of ULF magnetic field fluctuations observed on the ground (probably, generated in the magnetosphere) a few days before an EQ. Schekotov et al. (2006) have performed an extensive study on this effect on the basis of observations in Russia (Karymshiro) during the four-year period of June 21, 2000 through June 6, 2004 and those in Japan (Matsukawa) during the two-year 
period from October 22, 2001 to October 26, 2003. Their result was based on the analyses of 38 EQs (mainly oceanic EQs) with $\mathrm{M}$ in a range from 4.5 to 7.0 in Russia and of 22 separate EQs (mainly inland) with $\mathrm{M}$ from 5.5 to 8.3 in Japan. The basic properties of depression of ULF fluctuations they statistically confirmed, are summarized as follows (see also Molchanov \& Hayakawa, 2008).

- The noticeable ULF depression occurs 1-5 days before a separate EQ or a sharp growth of seismicity. It appears in the vicinity of local midnight and is observed only during 1-2 nights before an EQ.

- This ULF magnetic field reduction is especially remarkable at the frequencies of $\sim 0.03-0.05 \mathrm{~Hz}(30-50 \mathrm{mHz})$ and also in the horizontal components.

- The value of ULF depression is linearly dependent on the seismic energy of a forthcoming EQ at the observation point.

The construction of this paper is as follows. First we report on the successful detection of ULF depression for the huge 2011 Japan oceanic EQ. In order to examine whether this kind of ULF depression is universal for other oceanic EQs, we have examined the ULF fluctuation data for additional two huge EQs $(M \cong 8)$ in the Kurile islands again of the plate type. It is found that similar ULF depressions have been identified for these EQs as well, and we can conclude that ULF depression is universal even for oceanic EQs.

\section{ULF Depression for the 2011 Japan EQ}

We first present our result of ULF depression for the case of a recent violent Japan EQ (M=9) happened on March 11, 2011. We indicate the ULF data used, analysis period and data analysis procedure, because these are exactly the same for other two EQs in the Kurile islands to be discussed in the next section.

\subsection{ULF Data Used and Analysis Period}

One of the main problems was to find the desired data, which were found on the site of World Data Center (WDC) for Geomagnetism, Kyoto. The data from the WDC are given in the format of IAGA (International Association of Geomagnetism and Aeronomy) 2000, where the magnetic field is represented by four components: Horizontal $(\mathrm{H})$, declination (D), vertical $(\mathrm{Z})$ and total field $(\mathrm{F})$. The period of data analysis is 6 months from December 1, 2010 to May 31, 2011.

The data are available from three magnetic observatories; Memambetsu (abbreviated as MMB in the following), Kakioka (KAK) and Kanoya (KNY) as black diamonds in Figure 1. The sampling frequency of magnetometers at all of these stations is equal to $1 \mathrm{~Hz}$. The positions and magnitudes of EQs with $\mathrm{M}>7$ and with depth smaller than $100 \mathrm{~km}$, are also indicated as circles in the same figure. The center of a circle indicates the EQ epicenter. Its size is proportional to EQ magnitude, and the color refers to the depth. We have used the seismic data from the ANSS (Advanced National Seismic System) worldwide earthquake catalog. The main shock took place at 14:46:18 LT (local time) on March 11, 2011 with its epicenter at the geographic coordinates $\left(36^{\circ} 06^{\prime} \mathrm{N}, 142^{\circ} 52^{\prime} \mathrm{E}\right)$ as shown in Figure 1. The magnitude was $\mathrm{M}=9$ and the depth was about $20 \mathrm{~km}$. This is a very typical oceanic EQ of the plate type, being very different from the extensively-studied fault-type EQs such as the Kobe EQ. The distance of each magnetic observatory from the epicenter of the main shock is $640 \mathrm{~km}$ for MMB, $300 \mathrm{~km}$ for $\mathrm{KAK}$, and $1300 \mathrm{~km}$ for KNY, respectively.

In the following sections we present the data processing procedure, the analysis results, and summary and discussions. 


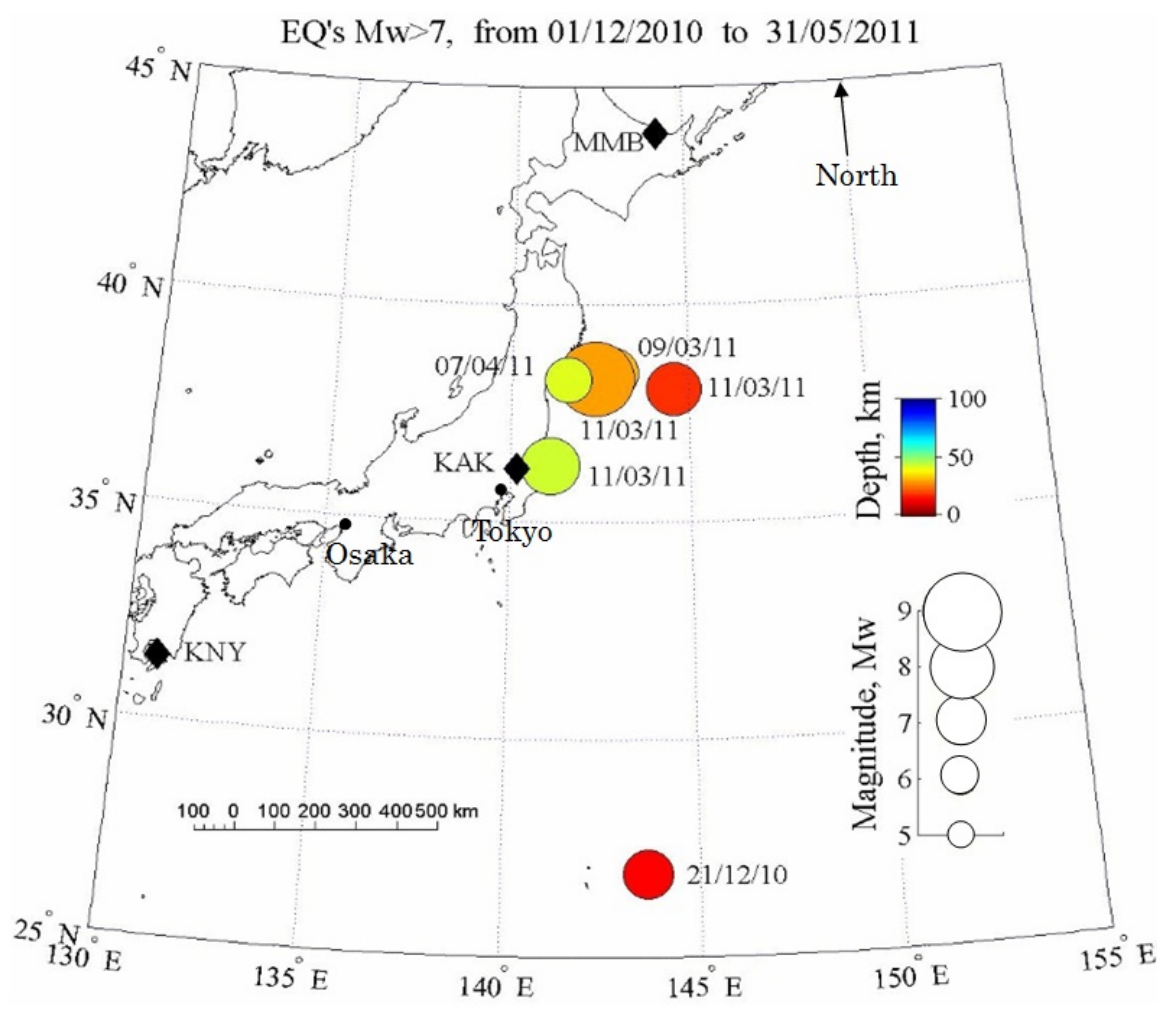

Figure 1. EQs and ULF observatories

Relative locations of three Japanese ULF observatories (KAK, MMB and KNY) and most powerful (M>7) EQs which occurred from December 1, 2010 to May 31, 2011. Our target EQ took place on March 11, 2011. Each circle corresponds to one particular EQ: the center of the circle is the EQ epicenter, its size indicates the EQ magnitude and its color indicates the depth.

\subsection{Data Analysis Procedure}

Following the main characteristic of our target phenomenon summarized in above Introduction, we are interested in the behavior of the horizontal $\mathrm{H}$ magnetic field component of ULF fluctuations (highly likely to be of magnetospheric origin). As already noted in the Introduction, the maximum depression in the horizontal component is usually observed in the immediate vicinity of local midnight. So the intervals of data analysis should be chosen carefully in such a way that all the observatories are situated at the same LT. We have to think of the LT intervals with low level of electromagnetic environmental noises (e.g., trains, electric motors, other similar equipments, etc.) and we choose the LT close to local midnight. The optimum time is found to lie in the vicinity of $\mathrm{LT}=3 \mathrm{~h}$ for each site as based on our previous measurements (Schekotov et al., 2006).

The value of absolute depression Dep in the horizontal component of ULF magnetic field variations is calculated as,

$$
\text { Dep }=\frac{1}{\left\langle U^{2}\right\rangle_{\Delta T}}
$$

where in the denominator we have estimated the squared output signal $U$ observed by the sensor in the frequency band of $\Delta \mathrm{F}=0.03-0.05 \mathrm{~Hz}$ averaged over the midnight interval $\Delta \mathrm{T}=3 \mathrm{~h} \pm 2 \mathrm{hr} \mathrm{LT}$. As a measure of relative depression (further simply depression) for the $\mathrm{i}$-th date, the following value

$$
\delta \operatorname{Dep}_{i}=\frac{\operatorname{Dep}_{i}-\frac{1}{N} \sum_{j=i-N}^{j=i-1} \operatorname{Dep}_{i}}{\frac{1}{N} \sum_{j=i-N}^{j=i-1} \operatorname{Dep}_{i}}
$$


is adopted to analyze. Here $\mathrm{N}$ is the filter parameter equal to the number of preceding days for averaging. In the present study $\mathrm{N}=5$ is taken. The denominator stands for the average, and the numerator indicates the deviation from the average. All the parameters in Equation (2), i.e. $\mathrm{N}, \Delta \mathrm{T}$ and $\Delta \mathrm{F}$ are chosen so as to maximize the success of forecast.

The above terminology of the success of forecast means that any precursor exceeds a certain threshold level, provided sufficient reliability of the forecast. Realibility of the forecast can be estimated by the method described by Console (2001), in which the value of probability gain (PG) is used as a criterion of the reliability. The PG depends on the statistics of detection (success rate, alarm rate), the total duration interval of observations, and the alarm interval of the precursor ( 5 days in the case of our ULF depression). Then the precursor is considered to be reliable if $P G>1$. It is possible to find the maximal value of PG by changing the threshold level, but this procedure is possible only for sufficient statistics.

Further comments on the parameters $(\mathrm{N}, \Delta \mathrm{T}$ and $\Delta \mathrm{F})$ in Equation (2) are given below one by one.

First as for the number of averaging days $\mathrm{N}$, in order to detect an impulsive signal (our depression) effectively it should be chosen to decrease the influence of long-term variation of ULF depression caused by the variation of background seismicity or the long-term variation of the magnetic fields. Actually $\delta$ Dep of Equation (2) works as a high-pass filter with cutoff frequency $\sim 1 / \mathrm{N}$. Now this parameter, $\mathrm{N}$ was chosen by changing its value in such a way to obtain higher ratio of the precursor value to the background for a previous remarkable EQ on December $21,2010$.

Then, the optimal time window $\Delta \mathrm{T}$ was estimated in our previous study, and it is found that the vicinity of local midnight is suitable. Unfortunately this choice was impossible in Japan, which is strongly contaminated by high level industrial interferences at that time. So that, the time window was shifted from local midnight to $3 \mathrm{~h}$ in the morning. We have used the same time window $(\Delta \mathrm{T}=3 \mathrm{~h} \pm 2 \mathrm{hr} \mathrm{LT})$ for all magnetometers, which gives us a possibility to obtain the response suitable for a comparison of results at the three observatories. However, the magnetometer at Kakioka has less "sensitivity" to the depression due to very high level of interference.

The last parameter of frequency window $\Delta \mathrm{F}$ was chosen from our previous results, which indicate maximal depression at these frequencies before an $\mathrm{EQ}$. We have tested the correctness of this choice for an example of the same previous remarkable EQ with $\mathrm{M}=7.4$ on December 21, 2010 (in Figure 1).

\subsection{Analysis Results}

The main result on the depression of ULF magnetic field component is summarized in Figure 2. The top panel indicates the temporal evolutions of Dst index as a measure of geomagnetic activity (in blue line) and the occurrence of EQs with magnitudes $\mathrm{M}>5$ (vertical line with a yellow star on the top). The temporal evolutions of depression at three Japanese observatories, $\delta \mathrm{Dep}_{\mathrm{MMB}} \delta \mathrm{Dep} \mathrm{p}_{\mathrm{KAK}}$ and $\delta \mathrm{De} \mathrm{p}_{\mathrm{KNY}}$ are illustrated in the second to fourth panels (as one datum per day). The depression is calculated according to the formula of Equation (2) in the frequency band $(\Delta \mathrm{F})$ of $0.03-0.05 \mathrm{~Hz}(30-50 \mathrm{mHz})$.

It is clear from the top panel of Figure 2 (on the occurrence of EQs) that the seismic activity was relatively low before the date of March 9, 2011. That is, during more than one month before March 9 there took place about 15 EQs with $\mathrm{M}<5$ and only two EQs with $\mathrm{M}>5.5$ in the region of our analysis. The maximum values of depression ( $\delta$ Dep) are found to lie in a range from 2 to 6 at different stations. Then, we pay our special attention to a significant and conspicuous peak on March 6, common to the three Japanese observatories in Figure 3. The extremal value of $\delta$ Dep is found to exceed several times all the previous values at all the observing sites. March 6 is 5 days before the main shock with magnitude $M=9$ and 3 days before a strong foreshock with $M=7.5$. The maximal peak of $\delta$ Dep $(\approx 14)$ is observed at KAK in Figure 2, which is closest to the EQ epicenter. The corresponding values of $\delta$ Dep are about 12 or so at the other two stations of MMB and KNY. When looking at the variation in $\delta$ Dep at three stations, the standard deviation of the fluctuation of $\delta$ Dep before the EQ is apparently much smaller (2-3 times) at KAK than at other two stations, probably reflecting the different electromagnetic noise environment. By taking the ratio of the peak value to the corresponding standard deviation at each station, we think that the peak in $\delta$ Dep at KAK should be much more significant than the observed value itself in Figure 2, as compared with other stations (MMB, KNY). The largest value of $\delta$ Dep at KAK is reasonably acceptable when thinking of its proximity to the EQ epicenter. 


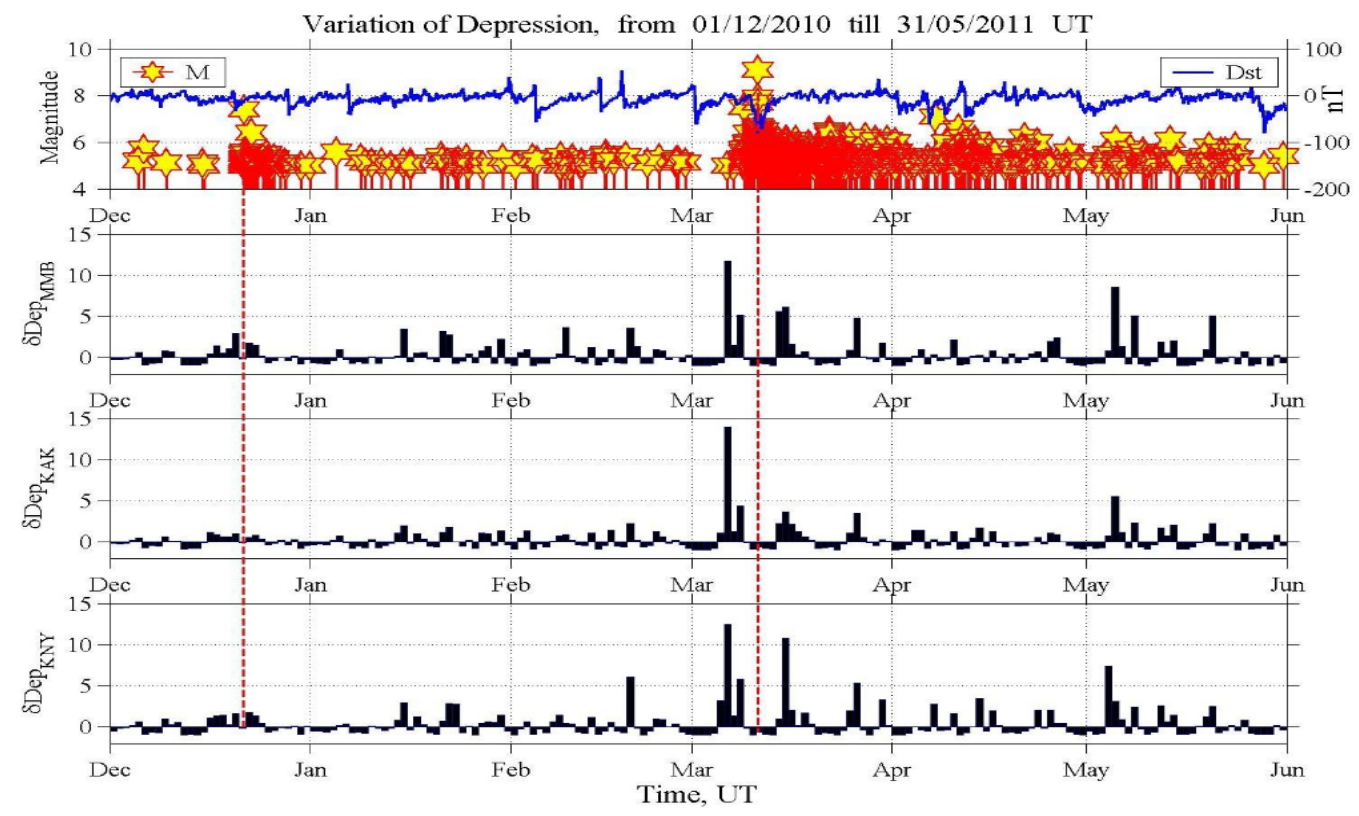

Figure 2. ULF magnetic field depression for the 2011 Japan EQ

Upper panel: Dst index of geomagnetic activity (in blue) and the occurrence of EQs with $\mathrm{M}>5$. A yellow star means an EQ, and its corresponding magnitude is given by its height. The 2nd, 3rd and 4th panels refer to the temporal evolutions of $\delta D e p_{M M B} \delta D e p_{K A K}$ and $\delta D e p_{K N Y}$ at three Japanese stations. Two vertical red dashed lines indicate the times of EQs occurred on December 21, 2010 and on March, 112011 (our main target).

After March 6 with the most enhanced $\delta$ Dep, the amplitude of $\delta$ Dep is found to decrease as seen in Figure 2, although the seismic acivity is still remaning high throughout the interval. Dst is chosen as a good indicator of geomagnetic activity at low and middle latitudes. There then seems to be no clear dependence of the magnitude of $\delta$ Dep peaks on the Dst index as seen in Figure 2 so that it appears that we can attribute the $\delta$ Dep peak on March 6 to the Japan EQ with $\mathrm{M}=9$. On the other hand, an increase in $\delta$ Dep is seen in the vicinity of two separate strong seismic events. The first of them is a rather weak response observed in the vicinity of EQ M=7.5 occurred on December 21, 2010 as in Figure 2. It is detected during the period of low background level of $\delta$ Dep. The second one of our main interest was observed before the beginning of the March swarm, so that it is reasonable for us to suppose that they are precursors of these two events. Small peaks are sometimes noticed in the subsequent interval after the main shock such as March 15, March 28 or so, which are likely attributed to the aftershock activity.

First of all, we try to summarize the observational facts on the depression of ULF horizontal (H) component possibly associated with the March 11 huge EQ in Japan.

1) The depression of ULF horizontal $(\mathrm{H})$ magnetic field component of magnetospheric origin was observed very conspicuously and simultaneously at three Japanese stations (KAK, MMB and KNY) on March 6, 2011.

2) This depression was found to be most enhanced at KAK, while the depression was also clearly detected at MMB and KNY (but to a less degree).

These properties of depression in the ULF horizontal magnetic field component observed in possible association with the huge Japan EQ, seem to be very consistent with the former statistical results by Schekotov et al. (2006), but the phenomenon itself is found to be very remarkable in the sense of such a large peak in the depression, probably in close association with the huge EQ. 


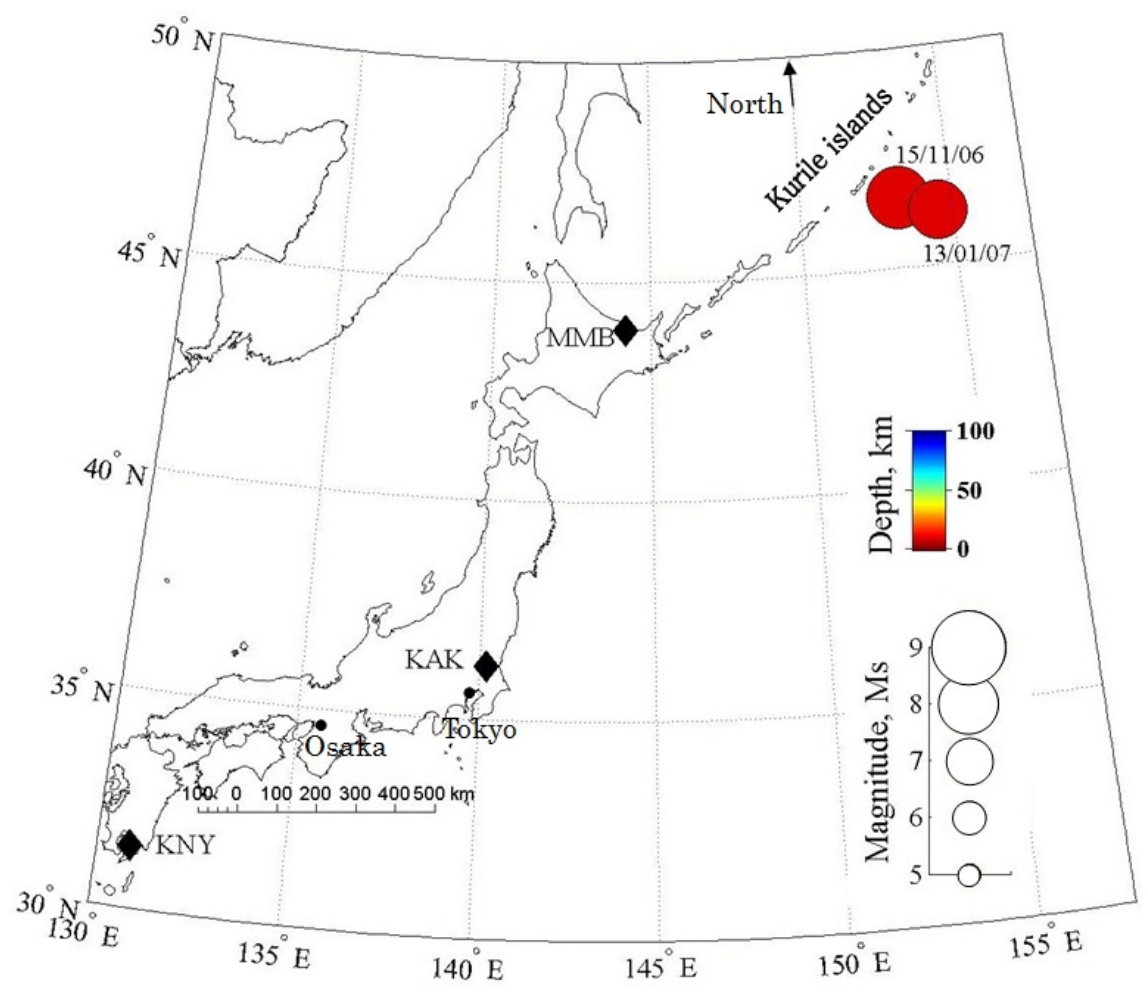

Figure 3. The epicenters of two huge EQs in the Kurile islands and three ULF observatories in Japan

\section{ULF Depression for Two Huge EQs in the Kurile Islands}

Two huge $(M \geq 8)$ EQs happened in the Kurile islands, which are summarized as follows. The 1st EQ happened on November 15, $2006(11 \mathrm{~h} 14 \mathrm{~m} 14 \mathrm{~s} \mathrm{LT})$ at the geographic coordinates $\left(46.59^{\circ} \mathrm{N}, 153.27^{\circ} \mathrm{E}\right)$. Its magnitude was $\mathrm{M}=8.3$ and its depth was $\sim 10 \mathrm{~km}$. The second $\mathrm{EQ}$, which was highly likely to be one of aftershocks of the $1 \mathrm{st} \mathrm{EQ}$, occurred on January 13, $2007(04 \mathrm{~h} 23 \mathrm{~m} 21 \mathrm{~s} \mathrm{LT})$ at the geographic coordinates $\left(46.24^{\circ} \mathrm{N}, 154.52^{\circ} \mathrm{E}\right)$, nearly at the same place as the 1st EQ (or main shock). The magnitude of this EQ was $\mathrm{M}=8.1$ and its depth was again $10 \mathrm{~km}$. The location of these two EQ epicenters is plotted in Figure 3 as circles. These are of the same type of oceanic EQs as the 2011 Japan EQ treated in the previous section. It is extremely worthwhile for us to investigate whether the similar ULF depression is really observable for these two EQs.

\subsection{ULF Data, Analysis Period and Data Analysis Procedure}

We have used the same ULF observatories in Japan as in the case of the 2011 Japan EQ; MMB, KAK, and KNY.

The analysis period is seven months from September 1, 2006 to March 31, 2007, including the two huge EQs in the Kurile islands.

Then, the analysis procedure is exactly the same as in the case of the 2011 Japan EQ in Section 2. That is, we have used the same LT intervals and also the same equation (2) with the same parameters.

\subsection{Observational Results for the Two EQs in the Kurile Islands}

Figure 4 illustrates the analysis results for the two huge EQs in the Kurile islands. In the top panel of Figure 4, we have plotted the geomagnetic activity measured by Dst and the EQ magnitude. The bottom three panels refer to the analysis results on the ULF depression during our period. The 2nd panel refers to the result for MMB in Hokkaido, the 3rd, KAK, and the fourth, KNY. The two vertical broken lines indicate the occurrence times of two EQs. 


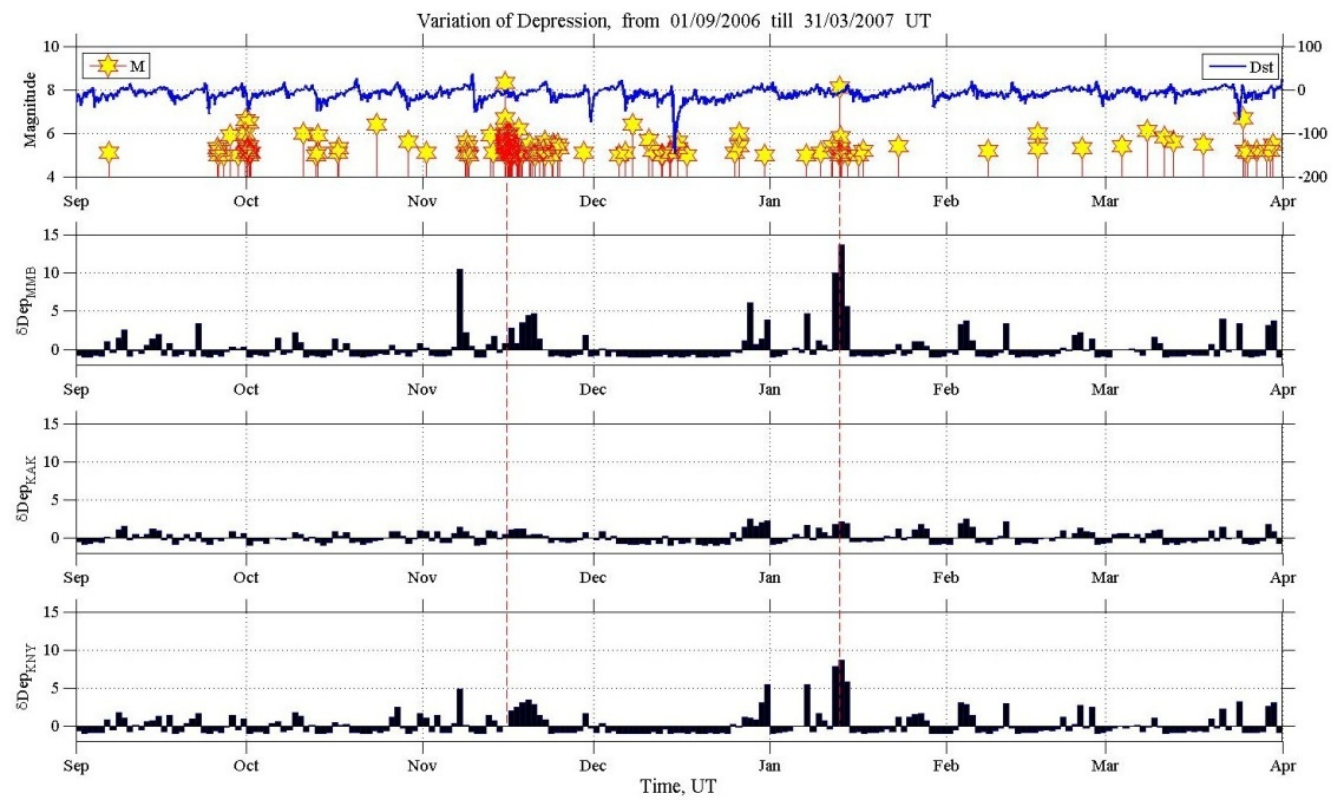

Figure 4. ULF magnetic field depressions for two EQs in the Kurile islands

The temporal evolutions of geomagnetic activity (Dst) and EQ magnitudes (top panel), and of $\delta$ Dep at three stations in Japan (2nd to 4th panels). The vertical dotted lines indicate the occurrence times of two EQs of our concern.

It is seen from Figure 4 that the ULF depression at MMB in Hokkaido exhibits remarkable changes just around the two EQs. As for the first, probably, main shock of the EQ, we have found a clear and isolated ULF depression about 10 days before the EQ. In addition to this precursory peak, there are observed some ULF depressions even after the EQ. As for the 2nd EQ (probably one of the aftershocks of the 1st EQ), there exist some anomalous behaviors at MMB. That is, the first anomaly (two peaks in $\delta$ Dep) in the end of December 2006 and an additional enhancement 6 days before the EQ. Also, we find a noticeable enhancement just around the EQ, $\delta$ Dep value being upto nearly 14 . How about the corresponding results for other stations (KAK and KNY) ? By looking at the $\delta$ Dep at KAK (3rd panel of Figure 4), we find that there is completely no response, no ULF depression even just around the two EQs. On the other hand, it looks that there are some corresponding responses at KNY because the peaks of $\delta$ Dep here at KNY are likely to be synchronous with those at MMB, even though the station of KNY is located in Kyushu island, far away from the EQ epicenter.

We can here summarize the ULF depression results for the two huge $(M \geqq 8)$ EQs in the Kurile islands.

1) The depression of ULF horizontal magnetic field (of magnetospheric origin) was observed very remarkably for the two huge EQs in the Kurile islands.

2) The characteristics of those ULF depressions seem to be quite similar to that for the 2011 Japan EQ, including the same frequency, nearly the same lead time, or so.

3) The depressions for these two EQs were found to be most enhanced at the station of MMB in Hokkaido, while some synchronous effect is detected as well at KNY.

\section{Discussion}

Below we try to discuss initially the results for the 2011 Japan EQ, and then we move on to the corresponding results for the two EQs in the Kurile islands.

Here we discuss whether the peak in ULF depression observed at Japanese observatories on March 6 is a possible precursor to the huge EQ on March 11, 2011. The EQ prediction requires the determination of the following three parameters: (1) “when?”, (2) “where?", and (3) "how big?", so that we discuss these EQ three parameters by making full use of the above observational facts.

The first question of the timing of our possible ULF anomaly is the simplest of the three parameters. Using the former statistical information about ULF depression by Molchanov et al. (2003) and Schekotov et al. (2006) and also summarized in Molchanov and Hayakawa (2008), we can suppose that an EQ will happen 1-5 days after the 
peak of $\delta$ Dep, i.e. from 7 to 11 of March, and the most probable day is 9 of March. As expected from the former results for moderate magnitude EQs, the first violent foreshock $(M=7.5)$ happened on March 9 and the main shock ( $M=9)$ happened on March 11.

The second question on the EQ localization, is more complicated because of high variability of spatial electromagnetic interferences and of the scale of the EQ preparation zone. Because of the first reason, the detection of the depression of ULF fluctuations depends strongly on the local electromagnetic interference. This makes ambiguous an estimate of distance to the EQ epicenter based on the characteristics of depressions at different observatories. The second reason leads only to the weak variation of depression at the distance of about $2000 \mathrm{~km}$ (the distance between MMB and KNY is about $1900 \mathrm{~km}$ ). We can assume as a preliminary estimate that the EQ place should be closer to KAK, because the peak of $\delta$ Dep there is higher than that at two other observatories (MMB and KNY). A similar conclusion follows from the analysis of seismicity before the activation on March 6. The maximal activity is seen north-east of KAK. After March 6 all the violent EQ events took place in the same region as seen in Figure 1.

Now we move on to the last question on the magnitude of a forthcoming EQ. We cannot use the linear dependence of $\delta$ Dep on the seismic energy because of high interference leading to the saturation of dependence at low magnitudes. However, an approximate linear relationship does exist between the value of $\delta$ Dep and EQ magnitude (Schekotov et al., 2006; Molchanov \& Hayakawa, 2008) and we can say, based on the level of answer to $\mathrm{M}=5.5 \mathrm{EQs}$, that the magnitude of an expected event is essentially higher, probably larger than 7. More information can be extracted from the small difference in depression between three stations located at distances almost two thousand $\mathrm{km}$. The expected magnitude for such a scale of preparation zone is in a range from 7 to 8 (Morgounov, 2004). The similar estimate is attempted by means of the theoretical expectation on the EQ preparation zone size by Dobrovolsky et al. (1979). Yamauchi et al. (2007) have estimated the size of ionospheric perturbations for some inland EQs in Japan, by making full use of the data from multiple VLF/LF propagation paths, and they have found that the experimental size of ionospheric perturbations is one half to one third of the theoretical value by Dobrovolsky et al. (1979). By using these informations, the experimental value in the present paper, $R_{0 b}=1000 \mathrm{~km}$ and on the assumption of a circular shape of the ionospheric perturbation, the expected magnitude (M) would be, at least, 7.3-7.7, so that this estimation seems to be consistent with the above estimate. These estimates proved to be realistic, although we do not know the real scale of the depression effect.

Here we discuss the corresponding results on ULF depression for the additional two huge EQs in the Kurile islands. It seems that the 2nd EQ is one of the aftershocks of the 1st EQ (main shock). Even in this situation, we are happy to have found very clear precursory enhancements of ULF magnetic field depression for both of EQs. Also, the characteristics of those ULF depressions are found to be very similar to those for the 2011 Japan EQ. So that, we can conclude that such a ULF depression seems to be a universal phenomenon even for huge oceanic EQs, and it is plausible that these effects might be a possible EQ predictor.

As for the generation mechanism on the depression of ULF magnetic field components, two hypotheses have already been proposed (Schekotov et al., 2006; Molchanov \& Hayakawa, 2008). The first possibility is the decrease in penetration coefficient of ULF fluctuations of Alfven mode waves originated in the magnetosphere due to the turbulent increase in the effective Pedersen conductivity in the ionosphere. The second hypothesis is a change in wave number (k) distribution of the source ionospheric turbulence. Whatever the hypothesis is more plausible (probably the 1st linear hypothesis is more acceptable), the depression of ULF horizontal magnetic field components of magnetospheric ULF fluctuations is apparently considered to be due to the precursory ionospheric disturbances; that is, a kind of seismo-lower-ionospheric effects. We have found the clear depression on March 6 for the 2011 Japan EQ. In good accordance with this inference, we have already found and published that the lower ionosphere was definitely perturbed on March 5 and 6 as based on subionospheric VLF/LF propagation on the propagation paths from the Americal transmitter (NLK, Seattle USA) to Japanese VLF/LF stations (Chofu, Kasugai and Kochi) (Hayakawa et al., 2012). Because there have been accumulated a lot of evidences of seismo-lower-ionospheric perturbations by means of subionospheric VLF/LF propagation anomalies (Hayakawa et al., 2010), it is highly likely that the lower ionosphere is really disturbed during these days, so that this is not an accidental coincidence and it would give a strong support to the ULF depression result.

Finally we have to mention that it seems that there are so many things to elaborate the present work, including the detailed study on the spatial scale of the phenomenon, what kind of ionospheric perturbation could result in the observed depression of the ULF horizontal magnetic field component? etc. 


\section{Acknowledgments}

The authors are grateful to Dr. N. Yagova for helpful advices. We then thank the whole staff of the WDC for Geomagnetism for providing the data of magnetic fields. Also we are grateful to ANSS for providing us with the data of seismicity. One of the authors $(\mathrm{MH})$ is grateful to Mayekawa Houonkai Foundation for its support.

\section{References}

Campbell, W. H. (2009). Natural magnetic disturbance fields, not precursors, preceding the Loma Prieta earthquake. J. Geophys. Res., 114, A05307. http://dx.doi.org/10.1029/2008JA013932

Console, R. (2001). Testing earthquake forecast hypotheses. Tectonophys, 338, 261-268. http://dx.doi.org/10.1016/S0040-1951(01)00081-6

Dobrovolsky, I. R., Zubkov, S. I., \& Myachkin, V. I. (1979). Estimation of the size of earthquake preparation. Pageoph, 117, 1025-1044. http://dx.doi.org/10.1007/BF00876083

Fraser-Smith, A. C. (2009). The ultralow-frequency magnetic fields associated with and preceding earthquakes. in "Electromagnetic Phenomena Associated with Earthquakes", Ed. by M. Hayakawa, Transworld Research Network, Trivandrum India, 1-20.

Fraser-Smith, A. C., Bernardy, A., McGill, P. R., Ladd, M. E., Helliwell, R. A., \& Villard, O. G. Jr. (1990). Low-frequency magnetic field measurements near the epicenter of the Ms 7.1 Loma Prieta earthquake. Geophys. Res. Lett., 17, 1465-1468. http://dx.doi.org/10.1029/GL017i009p01465

Hattori, K. (2004). ULF geomagnetic changes associated with large earthquakes. Terr. Atmos. Ocean. Sci., 15, 329-360.

Hayakawa, M., \& Molchanov, O. A. (Eds) (2002). Seismo Electromagnetics: Lithosphere-AtmosphereIonosphere Coupling. Terrapub, Tokyo, 477p.

Hayakawa, M., Hattori, K., \& Ohta, K. (2007). Monitoring of ULF (ultra-low-frequency) geomagnetic variations associated with earthquakes. Sensors, 7, 1108-1122. http://dx.doi.org/10.3390/s7071108

Hayakawa, M., Hobara, Y., Yasuda, Y., Yamaguchi, H., Ohta, K., Izutsu, J., \& Nakamura, T. (2012). A possible precursor to the 2011 3.11 Japan earthquake: Ionospheric perturbations as seen by subionospheric VLF/LF propagation. Ann. Geophysics, Special Issue, 55, 95-99.

Hayakawa, M., Kasahara, Y., Nakamura, T., Muto, F., Horie, T., Maekawa, S., ... Molchanov, O. A. (2010). A statistical study on the correlation between lower ionospheric perturbations as seen by subionospheric VLF/LF propagation and earthquakes. J. Geophys. Res., 115, A09305. http://dx.doi.org/10.1029/2009JA015143

Hayakawa, M., Kawate, R., Molchanov, O. A., \& Yumoto, K. (1996). Results of ultra-low-frequency magnetic field measurements during the Guam earthquake of 8 August 1993. Geophys. Res. Lett., 23, 241-244. http://dx.doi.org/10.1029/95GL02863

Kopytenko, Yu. A., Ismaguilov, V. S., \& Nikitina, L. V. (2009). Study of local anomalies of ULF magnetic disturbances before strong earthquakes and magnetic fields induced by tsunami. in "Electromagnetic Phenomena Associated with Earthquakes", Ed. by M. Hayakawa, Transworld Research Network, Trivandrum India, 21-40.

Kopytenko, Yu. A., Matiashvily, T. G., Voronov, P. M., Kopytenko, E. A., \& Molchanov, O. A. (1990). Discovering of ultra-low-frequency emissions connected with Spitak earthquake and its aftershock activity on data of geomagnetic pulsations observations at Dusheti and Vardzija. IZMIRAN Preprint No. 3a (888), $27 \mathrm{p}$.

Masci, F. (2011). On the seismogenic increase of the ratio of the ULF geomagnetic field components. Phys. Earth Planet. Inter., 187, 19-32. http://dx.doi.org/10.1016/j.pepi.2011.05.001

Molchanov, O. A., \& Hayakawa, M. (2008). Seismo-Electromagnetics and Related Phenomena: History and latest results. TERRAPUB, Tokyo, ISBN No.: 978-4-88704-143-1, 189p.

Molchanov, O. A., Kopytenko, Yu. A., Voronov, P. M., Kopytenko, E. A., Matiashvili, T. G., Fraser-Smith, A. C., \& Bernardy, A. (1992). Results of ULF magnetic field measurements near the epicenters of the Spitak $(\mathrm{M}=6.9)$ and the Loma-Prieta $(\mathrm{M}=7.1)$ earthquakes: Comparative analysis. Geophys. Res. Lett., 19, 1495-1498. http://dx.doi.org/10.1029/92GL01152

Molchanov, O. A., Schekotov, A. Yu., Fedorov, E. N., Belyaev, G. G., \& Gordeev, E. E. (2003). Preseismic ULF 
electromagnetic effect from observation at Kamchatka. Natural Hazards Earth Syst. Sci., 3, 1-7. http://dx.doi.org/10.5194/nhess-3-203-2003

Morgounov, V. A. (2004). Slip weakning, strain and short-term preseismic disturbances. Ann. Geophysics, 47(1), 133-149.

Pulinets, S., \& Boyarchuk, K. (2004). Ionospheric Precursors of Earthquakes. Berlin: Springer, 315p.

Schekotov, A., Molchanov, O. A., Hattori, K., Fedorov, E., Gladyshev, V. A., Belyaev, G. G., ... Hayakawa, M. (2006). Seismo-ionospheric depression of the ULF geomagnetic fluctuations at Kamchatka and Japan. Phys. Chem. Earth, 31, 313-318. http://dx.doi.org/10.1016/j.pce.2006.02.043

Yamauchi, T., Maekawa, S., Horie, T., Hayakawa, M., \& Soloviev, O. (2007). Subionospheric VLF/LF monitoring of ionospheric perturbations for the 2004 Mid-Niigata earthquake and their structure and dynamics. J. Atmos. Solar-terr. Phys., 69, 793-802. http://dx.doi.org/10.1016/j.jastp.2007.02.002 